NBER WORKING PAPER SERIES

\title{
MEASURING THE OUTPUT AND PRICES OF THE LOTTERY SECTOR: AN APPLICATION OF IMPLICIT EXPECTED UTILITY THEORY
}

\author{
$\mathrm{Kam} \mathrm{Yu}$ \\ Working Paper 14020 \\ http://www.nber.org/papers/w14020 \\ NATIONAL BUREAU OF ECONOMIC RESEARCH \\ 1050 Massachusetts Avenue \\ Cambridge, MA 02138
}

May 2008

The author wishes to thank Lottery Canada for providing the data on Lotto 6/49. The views expressed herein are those of the author(s) and do not necessarily reflect the views of the National Bureau of Economic Research.

NBER working papers are circulated for discussion and comment purposes. They have not been peerreviewed or been subject to the review by the NBER Board of Directors that accompanies official NBER publications.

(C) 2008 by Kam Yu. All rights reserved. Short sections of text, not to exceed two paragraphs, may be quoted without explicit permission provided that full credit, including $@$ notice, is given to the source. 
Measuring the Output and Prices of the Lottery Sector: An Application of Implicit Expected Utility Theory

Kam Yu

NBER Working Paper No. 14020

May 2008

JEL No. C43,D81,L83

\begin{abstract}
Using implicit expected utility theory, a money metric of utility derived from playing a lottery game is developed. Output of the lottery sector can be defined as the difference in utility with and without the game. Using a kinked parametric functional form, outputs of the Canadian Lotto 6/49 are estimated. Results show that this direct economic approach yield an average output which is almost three times of the official GDP, which takes total factor costs as output. A by-product of the estimation is an implicit price index for lottery, which can serve as a cost-of-living index for the CPI. The estimated price elasticity of demand -0.67 closely resembles results for the U.K. and Israel in previous studies.
\end{abstract}

Kam Yu

Lakehead University

kam.yu@lakeheadu.ca 


\title{
Measuring the Output and Prices of the Lottery Sector: An Application of Implicit Expected Utility Theory
}

\author{
Kam Yu*
}

November 30, 2006

\begin{abstract}
Using implicit expected utility theory, a money metric of utility derived from playing a lottery game is developed. Output of the lottery sector can be defined as the difference in utility with and without the game. Using a kinked parametric functional form, outputs of the Canadian Lotto 6/49 are estimated. Results show that this direct economic approach yield an average output which is almost three times of the official GDP, which takes total factor costs as output. A by-product of the estimation is an implicit price index for lottery, which can serve as a cost-of-living index for the CPI. The estimated price elasticity of demand -0.67 closely resembles results for the U.K. and Israel in previous studies.
\end{abstract}

JEL Classification: C43, D81, H50, L83, O47, P44

Keywords: system of national accounts, direct measurement, volume index, quantity index, choice under risk, lotteries, Lotto 6/49, gambling, non-expected utility theory.

\section{Introduction}

This paper studies the output and price measurement of the lottery sector using an economic approach. Perhaps as a result of the accumulating effects in jackpots when there are no major prize winners in previous weeks, lottery industries in Canada and elsewhere are growing steadily. In 1997, according to the Survey of Household Spending (SHS), 68.4\% of all households in Canada bought government-run pool and

*Lakehead University, e-mail: Kam.Yu@lakeheadu.ca. The author wishes to thank Lottery Canada for providing the data on Lotto 6/49. 
lottery tickets, with the average expenditure per household equals to $\$ 238$, which translates to $0.3 \%$ of total expenditure. Expenditure in gambling, however, has been found to be consistently under-reported in the SHS. The actual amount of money spent on gambling, according to revenue reported by the government, is three times the amount reported by households (Marshall, 1998, p.31). Therefore the lottery industry has become a significant part of the GDP, and a more accurate method of measuring its output is needed. Moreover, prices in any game of chance are not currently included in the consumer price index (CPI). If we are able to calculate the real output of lottery, then an implicit price index can also be computed. This price index can be used both as a deflator in the national account and as a subindex in the CPI.

In the theory of consumption under uncertainty, the typical consumer is traditionally assumed to follow an optimal statistical decision rule with risk-averse preferences. This leads to the well known expected utility hypothesis (EUH), in which the risk averseness is often assumed to be decreasing in wealth. A wealthy person is more willing to invest in a risky but high yield portfolio than an average person. The EUH has been successfully applied to problems in insurance and financial investment. Its linear structure, however, also implies that a risk-averse expected utility maximizer will never buy lottery tickets unless the payout prizes are exceedingly large. In reality we observe that consumers who are fully insured in their houses and cars also engage in a variety of gambling activities. Therefore we need a different approach other than the EUH. In the past two decades new theories on economic uncertainty have been developed. For example, Diewert (1995) shows that the real output of a simple gambling sector can be measured using implicit expected utility theory. It successfully models consumers' risk-averseness involving large portion of their wealth and at the same time captures the risk-seeking character involving small amount of money. In this paper, Diewert's model will be generalized from a simple two-outcome lottery to an $\mathrm{N}$-outcome one (the $6 / 49$ lotto has 6 outcomes with different payouts). The functional form of the estimating equation will be derived and estimated with Canadian data.

The portion of government output in the national accounts of industrialized countries has been increasing over the past several decades. There has been an ongoing debate on the concept and practice of measuring government output. Due to the absence of market prices in government services, statistical agencies traditionally use total factor costs as a proxy for the output. This practice has become less acceptable as the government sector has expanded. The Inter-Secretariat Working Group on National Accounts (1993) ${ }^{1}$ recommends that government output should be measured directly whenever possible. In fact, the statistical bureaus in Australia, U.K. and the Netherlands have switched to various forms of direct methods recently. In the case of government lotteries, the price of a lottery ticket is not the market price in the sense

\footnotetext{
${ }^{1}$ This manual is often referred to as SNA93.
} 
of quantity measurement. Therefore the total factor cost is usually taken as a proxy for output. This paper proposes a direct method of measuring government services in lotteries. Our results show that by using a direct utility approach, the measured output of Lotto 6/49 in Canada is three times higher than the official statistics. The estimated price elasticity of demand is found to be very similar to those of other countries.

The structure of the paper is as follows. Section 2 examines the classical and new economic theories of uncertainty and some of their applications. In section 3, we briefly discuss the gambling sector in Canada and apply the new theory to the economics of lottery. A money metric measure of the real output of the sector will be derived. In practice, a two-parameter equation is estimated using a nonlinear regression. The next step is to use the Canadian Lotto 6/49 as an example to test the feasibility of the model. The results are presented in section 4 . Finally, section 5 concludes.

\section{The Economic Analysis of Uncertainty: A Brief Review}

\subsection{The Expected Utility Hypothesis}

The classical analysis of economic uncertainty begins with Friedman and Savage (1948) and von Neumann and Morgenstern (1953). Their writings form the basis for what is generally known as expected utility hypothesis (EUH). The EUH has been successfully applied to a number of economic problems such as asset pricing and insurance. It has also been used as the premise in statistical decision theory. ${ }^{2}$ In the basic model, the uncertainty is represented by a set of simple lotteries $\mathcal{L}$ over a set of outcomes $\mathcal{C}$. A simple lottery $L \in \mathcal{L}$ in the discrete case can be represented by a vector of outcomes and a vector of probabilities, that is, $L=$ $\left(p_{1}, p_{2}, \ldots, p_{N}\right)$ where $\sum_{i=1}^{N} p_{i}=1$. Therefore outcome $C_{i} \in \mathcal{C}$ will occur with probability $p_{i}, i=1, \ldots, N$. A consumer or a decision maker is assumed to have a complete and transitive preference structure $\succsim$ on $\mathcal{L}$. In addition, the preferences are supposed to be continuous and independent. The latter assumption means that for all $L, L^{\prime}, L^{\prime \prime} \in \mathcal{L}$, and $0<\alpha<1$, we have

$$
L \succsim L^{\prime} \quad \text { if and only if } \quad \alpha L+(1-\alpha) L^{\prime \prime} \succsim \alpha L^{\prime}+(1-\alpha) L^{\prime \prime} .
$$

Therefore, the ranking on $L$ and $L^{\prime}$ remains unchanged if we mix the lotteries with another one to form compound lotteries. Together, the continuity and independence

\footnotetext{
${ }^{2}$ See, example, Luce and Raiffa (1957) and Pratt, Raiffa, and Schaifer (1995).
} 
assumptions imply the existence of an expected utility function $U: \mathcal{L} \rightarrow \mathbb{R}$ such that

$$
U(L)=\sum_{i=1}^{N} u_{i} p_{i}
$$

where $u_{i}, i=1, \ldots, N$ are utility numbers assigned to the outcomes $C_{i} \in \mathcal{C}$ respectively. Therefore,

$$
L \succsim L^{\prime} \quad \text { if and only if } \quad U(L) \geq U\left(L^{\prime}\right) .
$$

The independence assumption, which gives rise to the linear structure of the expected utility function, has been controversial from the beginning. Samuelson (1952) defends the independence axiom by arguing that in a stochastic situation, the outcomes $C_{i}$ are mutually exclusive and therefore are statistically independent. Consequently $U(L)$ must be additive in structure. Moreover, using a theorem by Gorman (1968), Blackorby, Davidson, and Donaldson (1977) show that continuity and independence imply that the utility structure under uncertainty is additively separable.

In spite of its solid theoretical foundation and normative implications, some applications of the EUH do not conform well with real behaviour. ${ }^{3}$ The most serious challenge is the Allais (1953) paradox, which can be illustrated by the following example. It involves decisions over two pairs of lotteries. The outcomes are cash prizes $\left(C_{1}, C_{2}, C_{3}\right)=(\$ 2,500,000 ; \$ 500,000 ; 0)$. In the first pair, the subjects are asked to choose between $L_{1}=(0,1,0)$ and $L_{1}^{\prime}=(0.10,0.89,0.01)$. That is, $L_{1}$ is getting $\$ 500,000$ for sure, while $L_{1}^{\prime}$ has a $10 \%$ chance of winning $\$ 2,500,000,89 \%$ chance of winning $\$ 500,000$, and a $1 \%$ chance of winning nothing. The second part involving choosing between $L_{2}=(0,0.11,0.89)$ and $L_{2}^{\prime}=(0.10,0,0.90)$. Allais claims that most people choose $L_{1}$ and $L_{2}^{\prime}$. This contradicts the EUH since if we denote $u_{25}, u_{05}$, and $u_{0}$ to be the utility numbers correspond to the three prizes, then $L_{1} \succ L_{2}$ means that

$$
u_{05}>0.1 u_{25}+0.89 u_{05}+0.01 u 0 .
$$

Adding $0.89 u_{0}-0.89 u_{05}$ to both sides of the above inequality gives

$$
0.11 u_{05}+0.89 u_{0}>0.1 u_{25}+0.9 u_{0}
$$

This implies people should choose $L_{1}^{\prime}$ instead of $L_{2}^{\prime}$.

The linear structure of the EUH also implies that a risk averse consumer will never gamble, even for a fair game, no matter what the degree of risk aversion the consumer has. ${ }^{4}$ Friedman and Savage (1948) try to correct this problem by proposing a utility function $u$ with concavity varying with wealth level. This ad hoc fix does

\footnotetext{
${ }^{3}$ See, for example, Machina (1982), Rabin (2000), and Rabin and Thaler (2001).

${ }^{4}$ See Diewert (1993), p. 425. Rabin and Thaler (2001) provide numerical illustrations on the absurdity of some implications of the EUT. Also see comments by Watt (2002) and the response from Rabin and Thaler.
} 
not solve the problem for small gambles because both the normal wealth level and the payout prizes are far out in the concave section of $u$, given the insurance buying behaviour of the typical consumer. Cox and Sadiraj (2002) propose a new expected utility of income and initial wealth model, which assumes that the outcomes are order pairs of initial wealth and income (prize). Their model may have applications in other areas but they concede that 'the empirical failure of lottery payoffs is a failure of expected utility theory' (p. 16). The EUT may be a good theory in prescribing what people should behave, but it fail as a model to describe what people actually behave. Therefore in order to model a small gamble like the Lotto 6/49, we need a preference structure more flexible than the EUH.

\section{$2.2 \quad$ Non-expected Utility Theories}

Most of the theories developed to resolve the Allais paradox involve replacing or relaxing the independence axiom. ${ }^{5}$ For example, by taking a general approach to the idea of a mean function, Chew (1983) replaces the independence axiom with the 'betweenness' axiom. Instead of discrete probabilities on events in $\mathcal{C}$, let $\mathcal{L}$ now denotes the set of probability distribution functions. The betweenness axiom assumes that for all $F$ and $G$ in $\mathcal{L}, F \sim G$ requires that

$$
\alpha F+(1-\alpha) G \sim F, \quad 0<\alpha<1,
$$

where $F \sim G$ means $F \succsim G$ and $G \succsim F$, that is, the consumer is indifferent between the lotteries $F$ and $G$. This means that if a consumer is indifferent between lotteries $F$ and $G$, then every convex combination of $F$ and $G$ is indifferent to them as well. As a consequence, the indifference curves are still straight lines. The EUH, on the other hand, can be characterized as

$$
F \sim G \Rightarrow \alpha F+(1-\alpha) H \sim \alpha G+(1-\alpha) H, \quad 0<\alpha<1
$$

for any $H \in \mathcal{L}$. We can see that (3) reduces to $(2)$ if $H=F$. The involvement of a third lottery $H$ in (3) implies that the indifference curves are parallel straight lines. This additional restriction gives rise to the Allais paradox. The betweenness axiom together with other regularity conditions imply that preferences can be represented by a general mean function $M: \mathcal{L} \rightarrow \mathbb{R}$ such that ${ }^{6}$

$$
M(F)=\phi^{-1}\left(\frac{\int \alpha \phi d F}{\int \alpha d F}\right)
$$

where $\phi$ is a strictly monotonic and increasing function and $\alpha$ is a continuous and non-vanishing function, both on the domain of $F$. In (4), $\phi$ is similar to the von

\footnotetext{
${ }^{5}$ For surveys of the non-expected utility theories see Epstein (1992), Machina (1997), and Starmer (2000).

${ }^{6}$ For details see Chew (1983), Dekel (1986), and Epstein (1992).
} 
Neumann-Morgenstern utility function $u$ in (1), while $\alpha$ is an additional weighting function. The mean function $M$ can be interpreted as the certainty equivalent of $F{ }^{7}$ This two-parameter generalization of the EUH is less restrictive and can be used to resolve the Allais paradox.

Other developments in non-expected utility theory include, for example, Kahneman and Tversky's (1979) prospect theory, Gul's (1991) theory of disappointment aversion, and rank-dependent utility theory. ${ }^{8}$ In Gul's analysis, for example, a lottery is decomposed into an elation component and a disappointment component. A weak independence axiom is defined in terms of the elation/disappointment decompositions of lotteries. The combination of disappointment aversion and a convex von Neumann-Morgenstein utility function may represent preferences that are risk averse to even chance gambles and gambles with large loss with small probabilities, but risk loving to gambles winning large prize with small probability. Basically this provides the 'fanning out' effect to avoid the Allais paradox (Machina (1997)).

Using the contingent commodity approach of Arrow (1964) and Debreu (1959), Diewert (1993c) develops an implicit utility function as follows:

$$
\sum_{i=1}^{N} p_{i} \phi_{u}\left(x_{i}\right)-\phi_{u}(u)=0
$$

where $\phi: \mathbb{R}^{2} \rightarrow \mathbb{R}$ is function of the utility $u$ and $x_{i}$. In this formulation $x_{i}=f\left(y_{1}\right)$ where $y_{i}$ is a choice vectors in the state of nature $i, i=1, \ldots, N$, and $f$ is the consumer's certainty utility function. ${ }^{9}$ The function $u=F\left(y_{1}, y_{2}, \ldots, y_{N}\right)$ is the consumer's overall state contingent preference function. Notice that $u$ is implicitly solution of (5). For aggregation purpose, if we assume that the consumers have homothetic preferences, (5) reduces to

$$
\sum_{i=1}^{N} p_{i} \gamma\left(x_{i} / u\right)-\gamma(1)=0
$$

where $\gamma$ is an increasing and continuous function of one variable.

A common property of non-expected utility theories is that they can represent consumers with first order risk aversion, which implies that the risk premium of a small gamble is proportional to the standard deviation of the gamble. ${ }^{10}$ For a consumer with an expected utility function, on the other hand, second order risk

\footnotetext{
${ }^{7}$ In the context on equation (1), the certainty equivalent $\mu(L)$ of lottery $L$ is defined as $u(\mu(L))=$ $U(L)$. For a risk averse decision maker, the risk premium of $L$ is the difference between the expected value of $L$ and $\mu(L)$.

${ }^{8}$ For example, Yaari (1987), Chew and Epstein (1989a), Quiggin (1993), and Diecidue and Wakker (2001).

${ }^{9}$ The function $f$ is the counterpart of the von Neumann-Morgenstein utility function.

${ }^{10}$ See Segal and Spivak (1990) and Epstein (1992).
} 


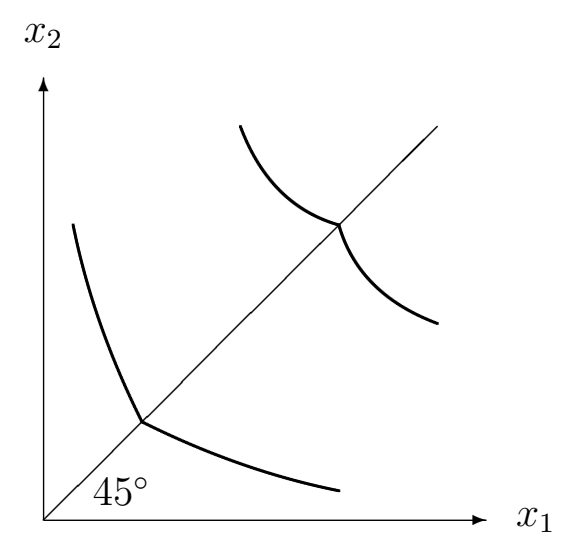

First Order

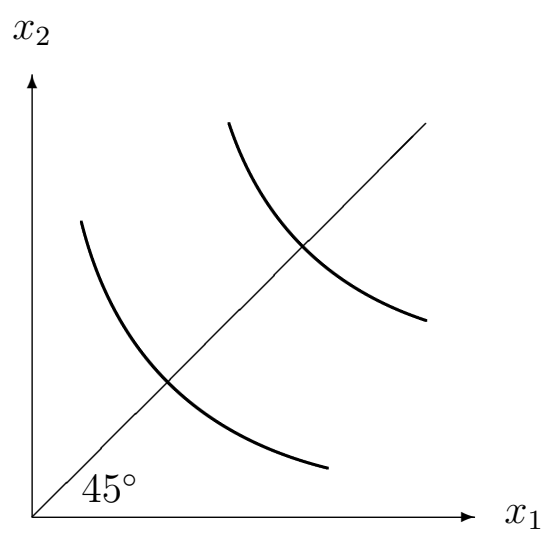

Second Order

Figure 1: First and Second Order Risk Aversion

aversion is exhibited, where the risk premium is proportional to the variance of the gamble. The difference can be illustrated graphically for the case $N=2$. In figure 1 , $x_{1}$ and $x_{2}$ represent the monetary outcome of states of nature 1 and 2 respectively. We assume that $p_{1}=p_{2}=1 / 2$ so that the indifference curves are symmetric about the 45 degree certainty lines. First order risk aversion is represented on the left with a kink at the certainty line, whereas second order aversion is represented by the smooth indifference curve on the right. ${ }^{11}$

\subsection{Applications of the New Theories}

The EUH has been applied to many areas in economics involving uncertainty. Since observed behaviour and experimental results sometimes contradicts the theory, it is interesting to see whether the non-expected utility theories can be successfully applied to those areas. In this section we review some applications of the newly developed theory to intertemporal consumption analysis, asset pricing, and output analysis in insurance and gambling.

Chew and Epstein (1989b) first extend the implicit expected utility to an axiomatic analysis of a two-period intertemporal preferences. They find that in order for the new theory to be admissible, one of the two axioms (consistency and timing indifference, which imply the EUH) has to be relaxed. The application is later extended to the case of multiple-period consumption-saving decision with a recursive structure (Chew and Epstein (1990) and Epstein (1992)). In traditional consumption-saving analysis, the use of a one parameter utility function cannot separate intertemporal substitution and the degree of risk aversion. For example, a typical intertemporal

\footnotetext{
${ }^{11}$ Machina(2001) provides a detailed discussion of kinks on an indifference curve.
} 
utility function is

$$
U\left(c_{0}, p\right)=f\left(c_{0}\right)+\beta E \sum_{t=1}^{\infty} \beta^{t-1} f\left(c_{t}\right)
$$

and

$$
f(c)= \begin{cases}c^{1-\alpha} /(1-\alpha), & 0<\alpha \neq 1 \\ \log c, & \alpha=1\end{cases}
$$

where $c_{t}$ is the consumption expenditure in period $t, t=0,1, \ldots, \infty, p$ is the probability measure of the future (uncertain) consumption vector $\left(c_{1}, c_{2}, \ldots\right)$, and $\beta \in(0,1)$ is the discount factor. Here $\alpha$ serves both as a relative risk aversion parameter and the reciprocal of the elasticity of substitution. By modifying the recursivity axiom, Chew and Epstein (1990) show that the two conceptions can be untangled by a class of utility functions that exhibits first order risk aversion, for example, the one suggested by Yaari (1987, p. 113). If the recursivity axiom is not assumed, however, then preferences may be inconsistent; that is, a consumption plan formulated at $t=0$ may not be pursued in subsequent periods. The situation can be modelled as a non-cooperative game between the decision maker at different times and a perfect Nash equilibrium is taken to describe the behaviour.

Using a similar approach, Epstein and Zin (1989) develop a generalized intertemporal capital asset pricing model (CAPM). This model is used to study the equity premium puzzle in the U.S., which has a historical average value of $6.2 \%$. Using calibration of preferences by simulation technique, empirical results by Epstein and Zin (1990) show that the use of non-expected utility function can explain at least a part (2\%) of the equity premium. Epstein and Zin (1991) also apply the intertemporal CAPM to update the permanent income hypothesis of Hall (1978). In this study the utility function takes the form

$$
U_{t}=W\left(c_{t}, \mu\left[\widetilde{U}_{t+1} \mid I_{t}\right]\right)
$$

where $\mu$ is the certainty equivalent of the recursive utility $\widetilde{U}_{t+1}$ at period $t+1$ given the information $I_{t}$ in period $t$. The separation of intertemporal substitution and risk aversion makes the model more realistic. The resulting estimating equation is the weighted sum of two factors: a relation between consumption growth and asset return (intertemporal CAPM), and a relation between the risk of a particular asset with the return of the market portfolio (static CAPM). They conclude that the expected utility hypothesis is rejected, but the performance of the non-expected utility model is sensitive to the choice of the consumption measure (non-durable goods, durable, services, etc.). Average elasticity of substitution is less than one and average relative risk aversion is close to one.

Using the implicit utility function as described in (5), Diewert (1993, 1995) outlines simple models for measuring the real outputs of the insurance and gambling sectors. Here we describe the model of a two-state lottery game. This simple model 
will be extended in the next section into a six-state lottery. The two-state lottery is $L=\left(p_{1}, p_{2}\right)$, with $p_{2}=1-p_{1}$. The corresponding outcomes are

$$
x_{1}=y-w, \quad x_{2}=y+R w
$$

where $y$ is the consumer's income, $w$ is the wager, and $R$ is the payout ratio. Assuming homothetic preferences, the implicit utility function $\phi_{u}$ can be written as $\gamma$ in $(6)$ :

$$
\phi_{u}(z)=\gamma(z / u)
$$

In order to provide a kink in the indifference curve, we employ the following functional form for $\gamma$ :

$$
\gamma(z)= \begin{cases}\alpha+(1-\alpha) z^{\beta}, & z \geq 1 \\ 1-\alpha+\alpha z^{\beta}, & z<1\end{cases}
$$

where $0<\alpha<1 / 2, \beta<1, \beta \neq 0$. The implicit expected utility in (5) for this game is

$$
p_{1} \phi_{u}\left(x_{1}\right)+p_{2} \phi_{u}\left(x_{2}\right)-\phi_{u}(u)=0 .
$$

Substituting $\gamma$ in (8) into (9) as $\phi_{u}$, we have, for $x_{1}<x_{2}$,

$$
u=\left[\delta x_{1}^{\beta}+(1-\delta) x_{2}^{\beta}\right]^{1 / \beta}
$$

where $\delta \equiv p_{1} \alpha /\left[p_{1}+\left(1-p_{1}\right)(1-\alpha)\right]$. Putting (7) into (10), the consumer's utility maximization problem is

$$
\max _{w}\left[\delta(y-w)^{\beta}+(1-\delta)(y+R w)^{\beta}\right]^{1 / \beta}
$$

where $0 \leq w \leq y$. The first order condition is

$$
\begin{aligned}
\frac{y+R w^{*}}{y-w^{*}} & =\left[\frac{1-\delta}{\delta} R\right]^{\frac{1}{1-\beta}} \\
& =\left[\frac{\left(1-p_{1}\right)(1-\alpha) R}{p_{1} \alpha}\right]^{\frac{1}{1-\beta}} \\
& \equiv b .
\end{aligned}
$$

Solving for the optimal $w^{*}$ we have

$$
w^{*}=\frac{y(b-1)}{b+R} .
$$

Since $y, R$, and $w^{*}$ are observable, we can calculate $b$ in each period. Then $\alpha$ and $\beta$ can be estimated with a regression model. Having estimated $\alpha$ and $\beta$, we can calculate the consumer's utility level without gambling:

$$
u^{0}=\left[\delta y^{\beta}+(1-\delta) y^{\beta}\right]^{1 / \beta}=y
$$


Similarly, the utility level with gambling is

$$
u^{*}=\left[\delta(y-w)^{\beta}+(1-\delta)(y+R w)^{\beta}\right]^{1 / \beta} .
$$

The real output of the gambling service is then

$$
Q=u^{*}-u^{0} .
$$

\section{Modelling the Gambling Sector}

\subsection{Gambling Sectors in Canada}

The gambling industry in Canada has been growing in size and in revenue over the last decade. For example, revenue increased from $\$ 2.7$ billion in 1992 to $\$ 7.4$ billion in 1998, while employment grew from 11,900 from 1992 to 39,200 in 1999. In 1992, government lotteries were the major component in all games of chances, representing $90 \%$ of all gambling returns. They peaked at $\$ 2.8$ billion and have been declining at a moderate rate. On the other hand, video lottery terminals (VLTs) and casinos have grown rapidly. In 1998 revenue from the latter has overtaken government lotteries as the dominant player (Marshall, 2000).

Government lotteries are administered by five regional crown corporations, namely, Atlantic Lottery Corporation, Loto-Québec, Ontario Lottery and Gaming Corporation, Western Canada Lottery Corporation, and British Columbia Lottery Corporation. Most of these corporations offer their own local lottery games. The national games, Lotto 6/49, Celebration (a special event lottery), and Super 7, however, are shared by all the corporations through the coordination of the Canadian Interprovincial Lottery Corporation, which was established in 1976 to operate joint lottery games across Canada. Lotto 6/49 games are held twice a week on Wednesday and Saturday. Forty five percent of the sales revenue goes to the prize fund. The fifth prize, which requires matching three numbers out of the six drawn, has a fixed prize of $\$ 10$. The prize fund, after subtracting the payout for all the fifth prizes, becomes the pool fund. This pool fund is divided among the other prizes by fixed shares as shown in Table 1 . The prize money is shared equally among the winners of a particular prize category. If there is no winner for the jackpot, the prize money will be accumulated (rollover) to the prize fund of the next draw. About $13.3 \%$ of the sales revenue is used as the administration and retailing costs. This portion is used by Statistics Canada as the output the Lotto 6/49 game in the GDP.

\subsection{The Output of Government Lotteries}

In this section we extend Diewert's (1995) simple model to the measurement problem of a common lottery sector. A typical game of lottery, for example Lotto 6/49 in 
Table 1: Prizes of Canadian Lotto 6/49

\begin{tabular}{lllc}
\hline Prize & Rule & Probability of Winning, $\pi_{i}$ & Share of the Pool Fund \\
\hline Jackpot & 6 numbers & 0.0000000715 & $50 \%$ \\
Second & 5 numbers + bonus & 0.000000429 & $15 \%$ \\
Third & 5 numbers & 0.00001802 & $12 \%$ \\
Fourth & 4 numbers & 0.0009686 & $23 \%$ \\
Fifth & 3 numbers & 0.01765 & $\$ 10$ \\
\hline
\end{tabular}

Canada, involve choosing six numbers out of 49. Five prizes are awarded according to the rules listed in Table $1 .{ }^{12}$ For example, the probability of winning the jackpot for one single ticket is $1 / C_{49}^{6}=1 / 13,983,816=0.0000000715$, a one in 14 million chance. The probability of the second prize is 6 times the probability of the jackpot, that is $6 / 13,983,816=0.000000429$, and so on. ${ }^{13}$ The following notation is used in the model:

$$
\begin{array}{lll}
w & =\text { wager } \\
p_{i} & =\text { probability of winning the } i \text {-th prize, } & i=1, \ldots, 5 \\
p_{6} & =\text { probability of not winning any prize } & \\
x_{i} & =\text { state contingent consumption, } & i=1, \ldots, 6 \\
y & =\text { real disposable income } & \\
R_{i}=\text { payout for the } i \text {-th prize, } & i=1, \ldots, 6 .
\end{array}
$$

Buying more than one ticket increases the chance of winning, therefore

$$
p_{i}=w \pi_{i}, i=1, \ldots, 5,
$$

where $\pi_{i}$ is the probability of winning the $i$-th prize for one single ticket. Also, we have

$$
p_{6}=1-\sum_{i=1}^{5} p_{i}=1-w \sum_{i=1}^{5} \pi_{i}
$$

and

$$
x_{i}=y+R_{i}-w, i=1, \ldots, 6 .
$$

We assume a representative consumer with homothetic preferences so that her state contingent preference function $u=F\left(x_{1}, \ldots, x_{6}, p_{1}, \ldots, p_{6}\right)$ can be defined implicitly in (6). Using the kinked functional form (8), (6) becomes

$$
\sum_{i=1}^{5} p_{i}\left[\alpha+(1-\alpha)\left(\frac{x_{i}}{u}\right)^{\beta}\right]+p_{6}\left[1-\alpha+\alpha\left(\frac{x_{6}}{u}\right)^{\beta}\right]-1=0 .
$$

\footnotetext{
${ }^{12}$ See Ziemba (1986).

${ }^{13}$ For details of computing all the probabilities see Hoppe (1996).
} 
Solving for $u$ and using (11), (12), and (13), we have

$$
u(w)=\left[\frac{(1-\alpha) w \sum_{i=1}^{5} \pi_{i}\left(y+R_{i}-w\right)^{\beta}+\alpha\left(1-w \sum_{i=1}^{5} \pi_{i}\right)(y-w)^{\beta}}{\alpha+(1-2 \alpha) w \sum_{i=1}^{5} \pi_{i}}\right]^{1 / \beta}
$$

The consumer's utility maximization problem is to maximize $u(w)$ subject to the constraint $0 \leq w \leq y$. For notational convenience, we define the following variables as

$$
\begin{aligned}
d & =y-w \\
p & =\sum_{i=1}^{5} \pi_{i} \\
q & =\sum_{i=1}^{5} \pi_{i}\left(y+R_{i}-w\right)^{\beta-1} \\
r & =\sum_{i=1}^{5} \pi_{i}\left(y+R_{i}-w\right)^{\beta}
\end{aligned}
$$

The first order condition can be written as

$\alpha(1-\alpha) r-\beta q(1-\alpha)[\alpha+(1-2 \alpha) w p] w-\alpha \beta(1-w p)[\alpha+(1-2 \alpha) w p] d^{\beta-1}-\alpha(1-\alpha) p d^{\beta}=0$.

Rearranging terms we get a quadratic equation in $w$ :

$$
\begin{gathered}
{\left[\beta p\left(\alpha(1-2 \alpha) p d^{\beta-1}-(1-\alpha)(1-2 \alpha)^{2} q\right)\right] w^{2}+\left[\alpha \beta\left(\alpha p d^{\beta-1}-(1-\alpha) q-(1-2 \alpha) p d^{\beta-1}\right)\right] w} \\
+\alpha\left[(1-\alpha) r-\alpha \beta d^{\beta-1}-(1-\alpha) p d^{\beta}\right]=0 .
\end{gathered}
$$

Solving for this quadratic equation give us the optimal level of wager:

$$
\begin{aligned}
w^{*}= & \left\{-\alpha \beta\left(\alpha p d^{\beta-1}-(1-\alpha) q-(1-2 \alpha) p d^{\beta-1}\right)\right. \\
& \pm\left[\left\{\alpha \beta\left(\alpha p d^{\beta-1}-(1-\alpha) q-(1-2 \alpha) p d^{\beta-1}\right)\right\}^{2}-\right. \\
& 4 \alpha\left[(1-\alpha) r-\alpha \beta d^{\beta-1}-(1-\alpha) p d^{\beta}\right] \\
& {\left.\left.\left[\beta p\left(\alpha(1-2 \alpha) p d^{\beta-1}-(1-\alpha)(1-2 \alpha) q\right)\right]\right]^{1 / 2}\right\} } \\
& / 2\left\{\beta p\left(\alpha(1-2 \alpha) p d^{\beta-1}-(1-\alpha)(1-2 \alpha) q\right)\right\}
\end{aligned}
$$

Equation (16) is the estimation equation for the parameters $\alpha$ and $\beta$, given the data in the other variables. Notice that $w$ appears in the right hand side of the equation through (15). But the effects of $w$ on $d, q$, and $r$ are negligible since the disposable income $y$ and the sum of $y$ and payout prizes $R_{i}$ are much larger than $w$. Another functional form, the kinked quadratic generating function

$$
\gamma(z)= \begin{cases}z+\alpha(z-1)+\beta(z-1)^{2}, & z \geq 1 \\ z, & z<1\end{cases}
$$

was attempted in addition to (8) but the analysis yielded no explicit solution for $w$.

The output of services provided by Lotto 6/49 is equal to the difference between utility level with the lotteries and utility without lottery using (14), ie,

$$
Q^{t}=u\left(w^{t}\right)-u(0)
$$




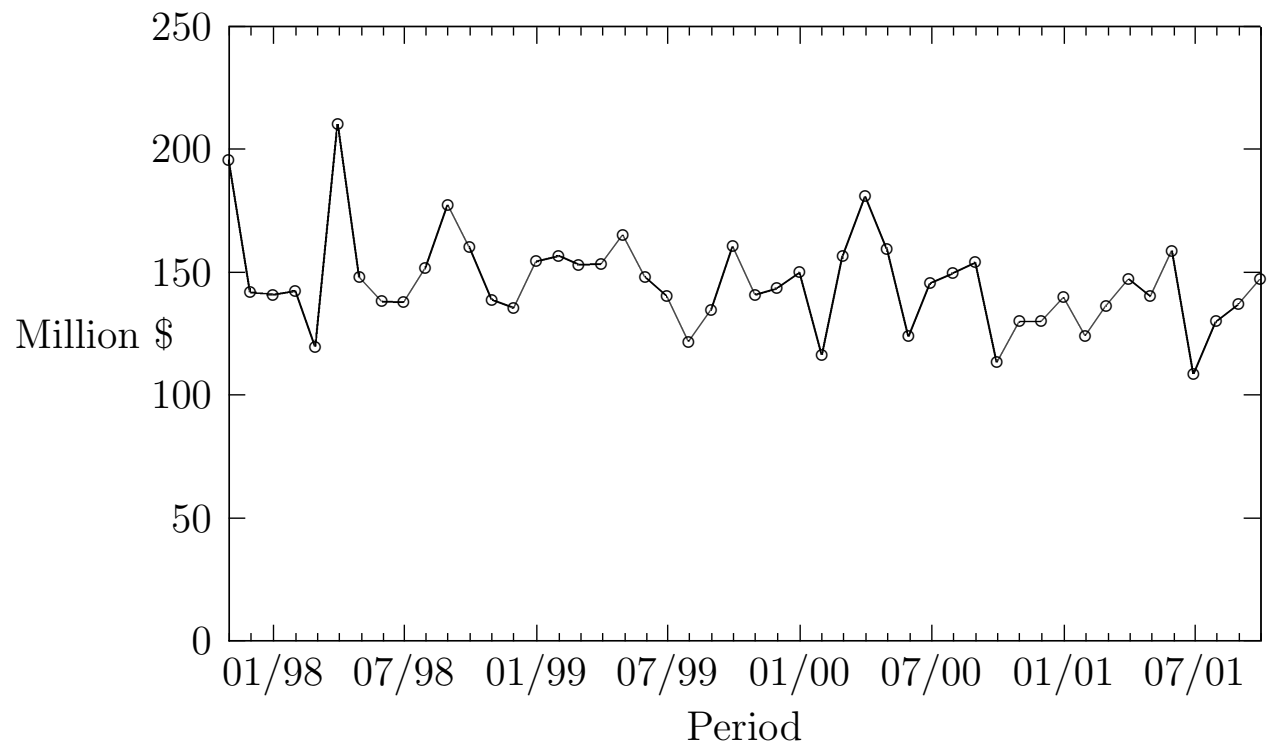

Figure 2: Monthly Sales of Lotto 6/49, 11/97 to 11/01

where $w^{t}$ is the observed wager in period $t$. An implicit price level can also be obtain as

$$
P^{t}=w^{t} / Q^{t}
$$

The resulting price index is an implicit cost-of-living index and can be included as a subindex in the CPI.

\section{Estimating the Output of Government Lotteries}

\subsection{Data}

Data on the winning numbers, payout prizes, and sales volume provided by Lottery Canada are available from November 11, 1997 to November 3, 2001 for Lotto 6/49, a total of 419 draws. Monthly data on the CPI and annual data on the number of households, personal disposable income, and participation rates in government lotteries are available from Statistics Canada. The sales volume of each draw is divided by the number of participating households, which gives the average wager per participating household, $w_{t}$. The average personal disposable income per household, adjusted by the CPI, is used as a proxy for $y_{t}$.

Figure 2 depicts the number of ticket sales for the sample period. We see that there is a downward trend in sales, reflecting the switch from government lotteries to other games like VLTs and casinos. Table 2 summarizes the average sales, number of winners and the payouts prizes of the observed draws. The biggest jackpot during 
Table 2: Descriptive Statistics of Canadian Lotto 6/49, 11/11/1997 to 3/11/2001

\begin{tabular}{lcccccc}
\hline & Sales & Jackpot & Second & Third & Fourth & Fifth \\
\hline Average No. of Winners & $16,717,385$ & 1.12 & 7.13 & 299 & 16036 & 292604 \\
Expected No. of Winners & & 1.20 & 7.17 & 308 & 16199 & 293287 \\
Prize (dollar) & & $3,249,108$ & 133,903 & 1,976 & 68 & 10 \\
\hline
\end{tabular}

the sample period was $\$ 15$ million, won by a single ticket on September 30, 2000. In Table 2 we also calculate the expected average number of winners using the probabilities in Table 1. We see that in each prize the observed average number of winners is slightly smaller than the expected number. One possible explanation of the difference is that some players pay more than one dollar for the same numbers, which often happens in lottery pools. Of the 419 draws, 151 end up with a rollover, which is $36 \%$. Given that the expected number of jackpot winners is 1.2 on the average, this rollover percentage seems high. In fact this agrees with previous observations in Canada (Ziemba (1986), Stern and Cover (1989)), the U.S. (Chernoff (1981)), and in the U.K. (Walker (1998), Simon (1999)) that people have 'conscious selection' (Cook and Clotfelter (1993)), that is, some numbers are on the average more popular than the others. ${ }^{14}$ For example, the six most popular numbers of Lotto 6/49 in Canada are $3,5,6,9,12$, and 13 in 1986 . One possible reason is that a lot of people use their birthdays as their choices. Therefore numbers starting from 32 onward are among the most unpopular numbers.

A lot of attention is concentrated on the jackpot prizes, particularly when there are rollovers and the pool fund becomes very big. Figure 3, however, shows that the average expected value is highest for the smallest prize. In the figure, EV1 to EV5 are the products of the payout prized and their respective probability of winning from March 4 to June 17, 1998. EV5 is constant because the payout is fixed at $\$ 10$. EV2 is higher than EV5 only in one draw, and EV1 is higher than EV5 in several occasions. The fifth prize has a high expected value because of the relatively high probability of winning. The pleasure and thrill from buying a lottery ticket, nevertheless, comes from big jackpot, which has a extremely low probability of winning. This is why a non-linear expected utility theory is needed to capture the risk-loving side of the consumers.

\subsection{Estimation and Results}

The parameters $\alpha$ and $\beta$ in (16) are estimated by a non-linear regression equation using the maximum likelihood method. Theoretically, demand depends on the expected values of the payout prizes $R_{1}, \ldots, R_{4}$, which in turn depend on the sales volume. The actual payout prizes, however, are used in the estimation. Following Walker (1998, p. 371), we invoke the rational expectations assumption, which implies

\footnotetext{
${ }^{14}$ For a general discussion see also Haigh (1997).
} 


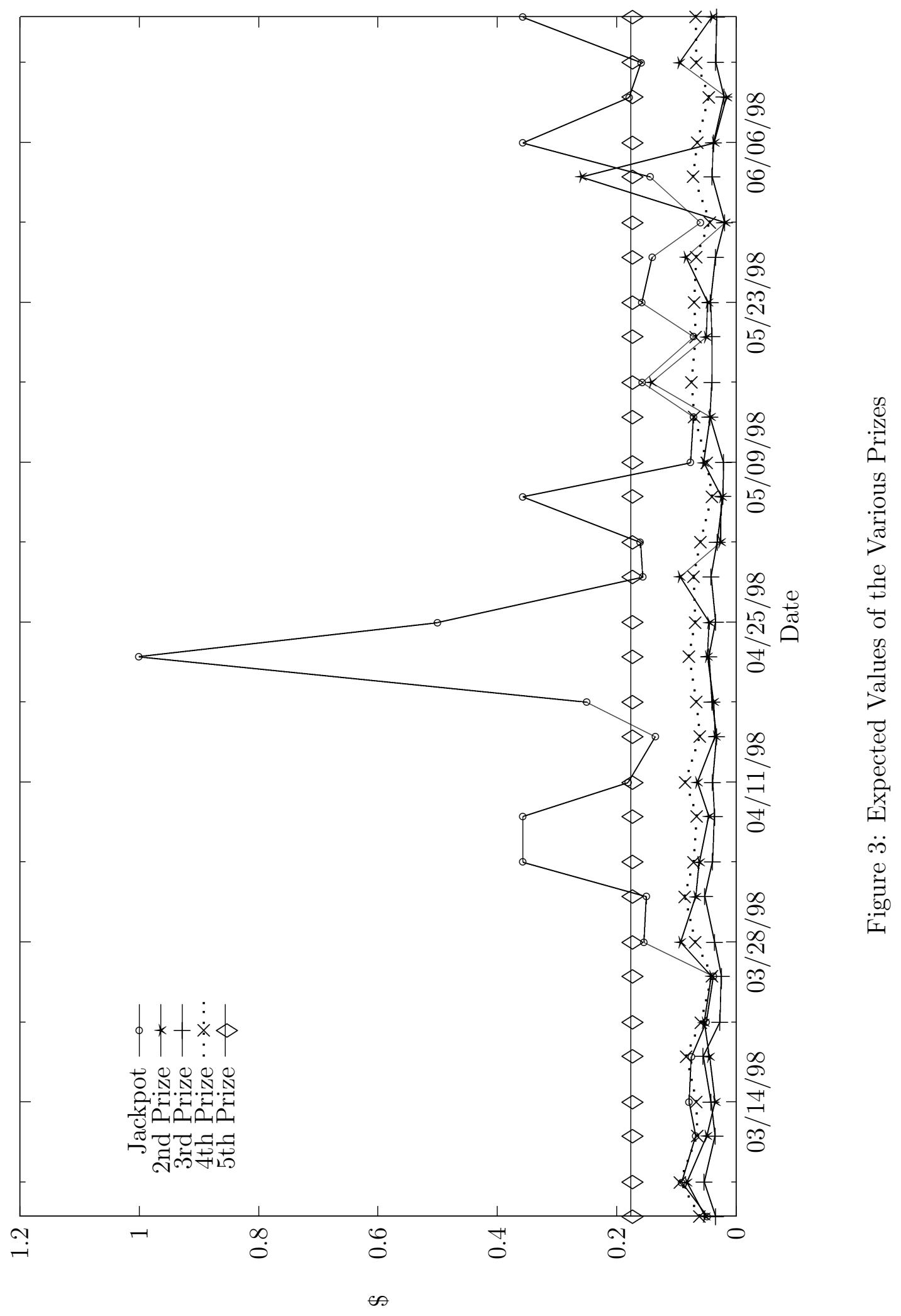




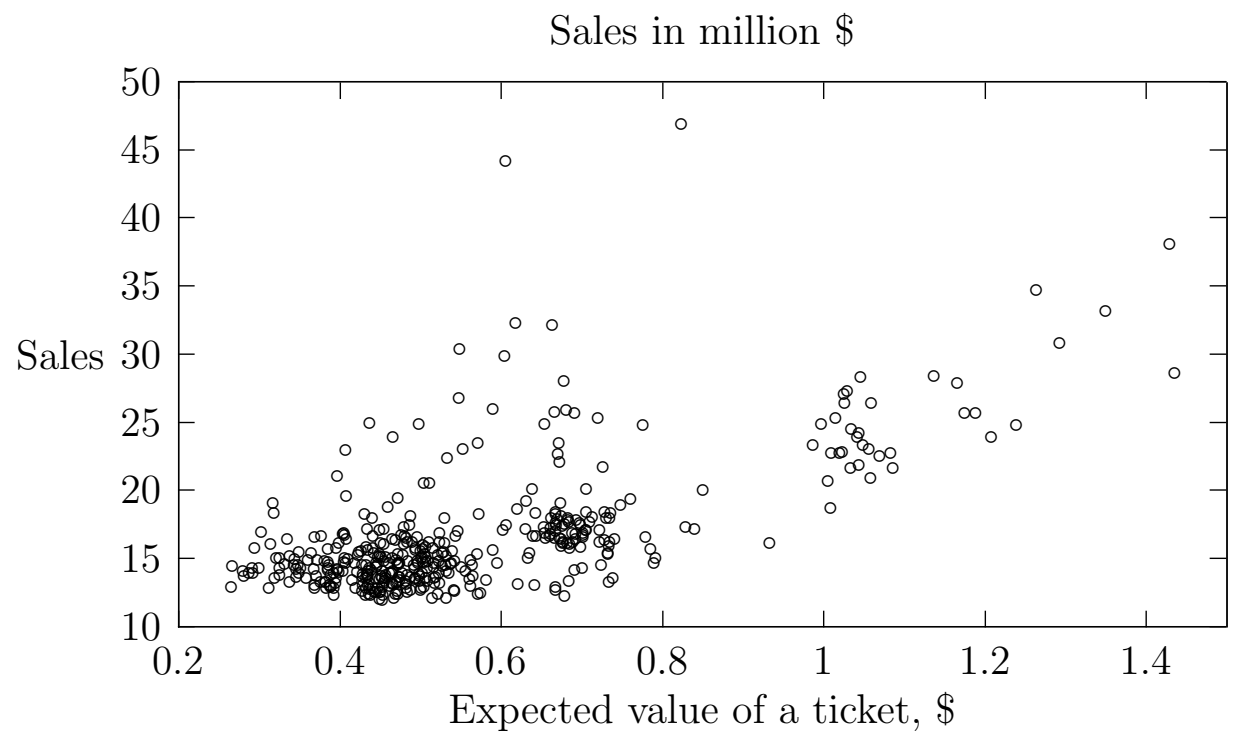

Figure 4: Sales and Expected Values of Lotto 6/49

that consumers do not make systematic mistakes in forecasting the sales. Figure 4 is a scatter plot of the sales volume against the ex post expected value of a ticket. It clearly shows the positive relation between the two. The estimated values of $\alpha$ and $\beta$ are 0.10458 and -31.986 , with standard errors equal to 0.003165 and 5.9527 respectively, which implies $t$-ratios of 33 and -5.4 . The estimated values satisfy the constraints $0<\alpha<1 / 2, \beta<1, \beta \neq 0$ in (8). These estimated values are then used to calculate the money metric utility $u\left(w_{t}\right)$ and the output level $Q^{t}$ of the lottery using (14) and (17) respectively for each draw. Outputs are aggregated into monthly results before the implicit price $P^{t}$ is calculated using (18). A fixed base price index is then calculated using the price level of November 1997 as the base. Figure 5 and 6 show the monthly price index and output of the Lotto 6/49 using this procedure. In Figure 6 the factor cost (13.3\% of sales revenue) is also included for comparison. Notice that the estimated output using the economic approach is much higher than the official GDP at factor cost but the former has a steeper downward trend. The average monthly output using the economic approach is $\$ 57.7$ million, compared to the official total cost approach of $\$ 19.4$ million.

We also estimate the elasticity of demand for the lottery using a simple log-linear model:

$$
\log Q=\log P+\log y+T
$$

where $T$ is a trend variable, which is included to capture change in taste over time. The resulting price elasticity of demand is -0.672 with a standard error of 0.017 . This result is comparable to the values of -0.66 estimated by Forrest et al (2001), 


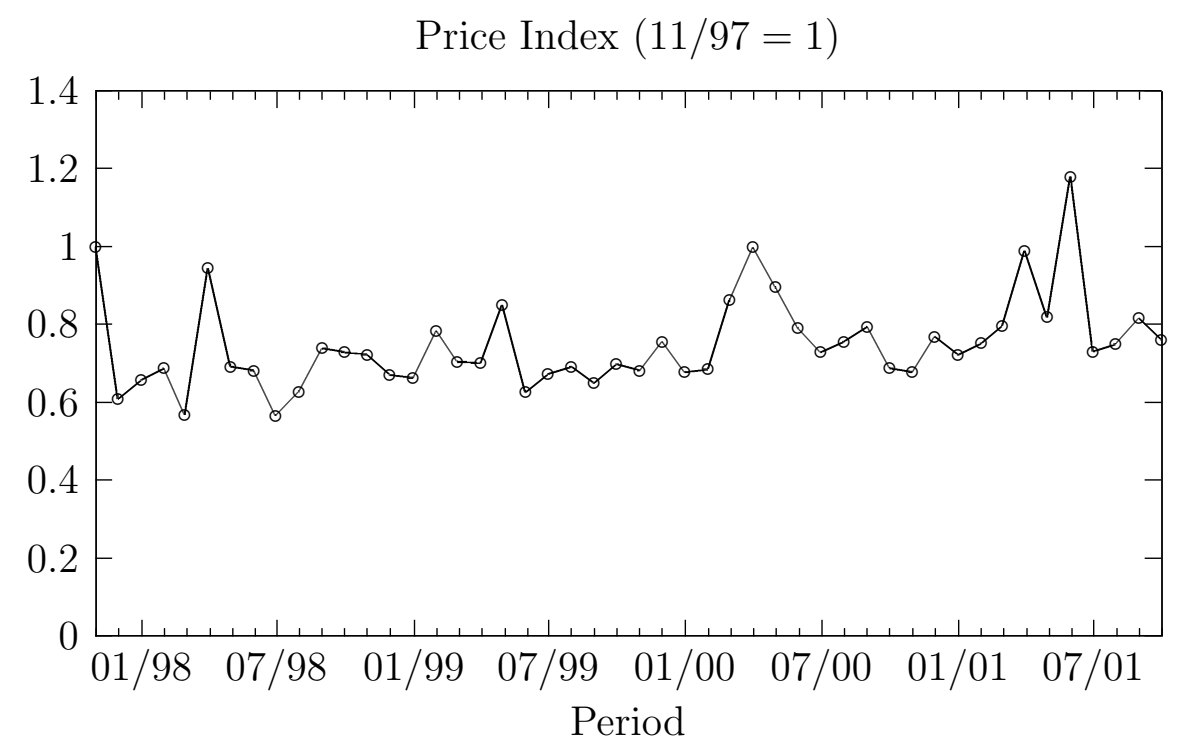

Figure 5: Price Index of Lotto 6/49

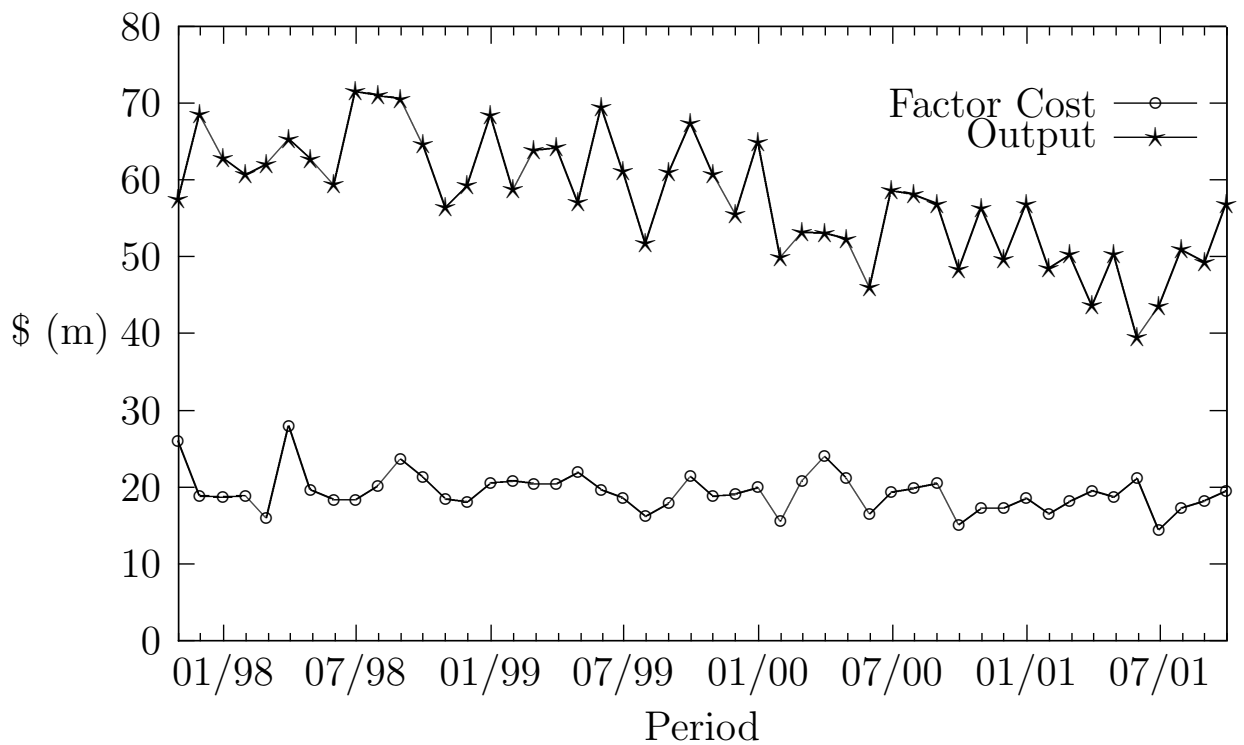

Figure 6: Output of Lotto 6/49 
who use a two-stage OLS estimation with the difference between the ticket price and the expected value as the effective price of lottery. Using a similar approach, Gully and Scott (1993) estimated the price elasticities of four state-operated lottos in the U.S., with results ranging from -0.40 to -2.5. Farrell and Walker (1999) used cross-sectional data to study the demand for lottery in the U.K. using the Heckman selection model. Their estimated price elasticity was -0.763. Also, Beenstock and Haitovsky (2001) study the demand for lotto in Israel using time series data, with the estimated long-run price elasticity equal to -0.65. It is surprising that these results, although differing in methods, nature of data, and countries, show very close estimates of price elasticities of demand.

\section{Conclusion}

The classical expected utility hypothesis fails to capture a consumer's risk averse behaviour in facing big losses with small probabilities and the risk loving behaviour involving large gain with small probability. New non-expected utility theories have been developed to overcome the difficulty. In this paper we have applied the implicit expected utility theory to the problem of measuring outputs of lotteries. The results show that output levels of Lotto 6/49 in Canada is almost three times higher than the official statistics, which uses the total cost of providing the service approach as output measurement principle. This kind of direct economic approach is recommended by SNA93 for government and non-profit organization output measurement. The method developed here can be potentially applied to other games of chance. ${ }^{15}$ The estimated price elasticity of demand for lottery in Canada is close to that of the U.K. and Israel in previous studies.

\section{References}

Allais, M. (1953) 'Le Comportement de L'homme Rationnel Devant le Risque: Critique des Postulats et Axiomes de L'ecole Americaine,' Econometrica, Vol. 21, No. 4, 503-546.

Arrow, K.J. (1964) 'The Role of Securities in the Optimal Allocation of Risk-bearing,' Review of Economic Studies, Vol.31, No. 2, 91-96.

Beenstock, Michael and Yoel Haitovsky (2001) 'Lottomania and other anomalies in the market for lotto,' Journal of Economic Psychology, 22, 721-744.

Blackorby, Charles, Russel Davidson, and David Donaldson (1977) 'A homiletic Exposition of the Expected Utility Hypothesis,' Economica, 44, 351-358.

\footnotetext{
${ }^{15}$ See Dubins and Savage (1965) and Richard Epstein (1977) for the mathematical analysis of a whole variety of games.
} 
Chernoff, Herman (1981) 'How to Beat the Massachusetts Numbers Game,' Mathematical Intelligencer, Vol.3, No.4, 166-172.

Chew, Soo Hong (1983) 'A Generalization of the Quasilinear Mean with Applications to the Measurement of Income Inequality and Decision Theory Resolving the Allais Paradox,' Econometrica, Vol. 51, No. 4, 1065-1092.

Chew, S.H. and L.G. Epstein (1989a) 'A Unifying Approach to Axiomatic Non-expected Utility Theories,' Journal of Economic Theory, 49, 207-240.

Chew, S.H. and Larry G. Epstein (1989b) 'The Structure of Preferences and Attitudes towards the Timing of the Resolution of Uncertainty,' International Economic Review, Vol.30, No. 1, 103-117.

Chew, Soo Hong and Larry G. Epstein (1990) 'Nonexpected Utility Preferences in a Temporal Framework with an Application to Consumption-Savings Behaviour,' Journal of Economic Theory, 50, 54-81.

Cook, Philip J. and Charles T. Clotfelter (1993) 'The Peculiar Scale Economies of Lotto,' American Economic Review, Vol. 83, No. 3, 634-643.

Cox, James C. and Vjollca Sadiraj (2002) 'Risk Aversion and Expected Utility Theory: Coherence for Small- and Large-Stakes Gambles,'Mimeo, University of Arizona.

Debreu, Gerard (1959) Theory of Value, New Haven: Yale University Press.

Dekel, Eddie (1986) 'An Axiomatic Characterization of Preferences under Uncertainty: Weakening the Independence Axiom,' Journal of Economic Theory, 40, 304-318.

Diecidue, Enrico and Peter P. Wakker (2001) 'On the Intuition of Rank-Dependent Utility,' Journal of Risk and Uncertainty, 23:3, 281-298.

Diewert, W.E. (1993) 'Symmetric Means and Choice under Uncertainty,' in W.E. Diewert and A.O. Nakamura, eds, Essays in Index Number Theory, Vol.1, Amsterdam: North-Holland, 335-433.

Diewert, W. Erwin (1995) 'Functional Form Problems in Modeling Insurance and Gambling,' Geneva Papers on Risk and Insurance Theory, 20, 135-150.

Dubins, Lester E. and Leonard J. Savage (1965) How to Gamble If You Must, New York: McGraw-Hill Book Co. 
Epstein, Larry G. (1992) 'Behavior under Risk: Recent Developments in Theory and Applications,' in Jean-Jacques Laffont, ed, Advances in Economic Theory, Sixth World Congress, Vol. II, Cambridge: Cambridge University Press, 1-63.

Epstein, Larry G. and Stanley E. Zin (1989) 'Substitution, Risk Aversion, and the Temporal Behavior of Consumption and Asset Returns: A Theoretical Framework,' Econometrica, Vol. 57, No. 4, 937-969.

Epstein, Larry G. and Stanley E. Zin (1990) 'First-Order Risk Aversion and the Equity Premium Puzzle,' Journal of Monetary Economics, 26, 387-407.

Epstein, Larry G. and Stanley E. Zin (1991) 'Substitution, Risk Aversion, and the Temporal Behavior of Consumption and Asset Returns: An Empirical Analysis,' Journal of Political Economy, Vol. 99, No. 2, 263-286.

Epstein, Richard A (1977) The Theory of Gambling and Statistical Logic, New Yorker: Academic Press.

Farrell, Lisa and Ian Walker (1999) 'The Welfare Effects of Lotto: Evidence from the UK,' Journal of Public Economics, 72, 99-120.

Forrest, David, O. David Gulley, and Robert Simmons (2000) 'Elasticity of Demand for UK National Lottery Tickets,' National Tax Journal, Vol. LIII, No. 4, Part $1,853-863$.

Friedman, Milton and L. J. Savage (1948) 'The Utility Analysis of Choices Involving Risk,' Journal of Political Economy, Vol. LVI, No. 4, 279-304.

Gorman, W. M. (1968) 'The Structure of Utility Functions,' Review of Economic Studies, Vol. 35, No.4, 367-390.

Gul, Faruk (1991) 'A Theory of Disappointment Aversion,' Econometrica, Vol. 59, No. 3, 667-686.

Gulley, O. David and Frank A. Scott, Jr. (1993) 'The Demand for Wagering on StateOperated Lotto Games,' National Tax Journal, Vol. 45, No. 1, 13-22.

Haigh, John (1997) 'The Statistics of the National Lottery,' Journal of the Royal Statistical Society, A, 160, Part 2, 187-206.

Hall, Robert E. (1978) 'Stochastic Implications of the Life Cycle-Permanent Income Hypothesis: Theory and Evidence,' Journal of Political Economy, Vol.86, No. 6, 971-987. 
Hoppe, Fred M. (1996) 'Mathematical Appendix to the Maclean's Magazine article by John Schofield, November 4, 1996,' Department of Mathematics, McMaster University, http://www.math.mcmaster.ca/fred/Lotto/.

Inter-Secretariat Working Group on National Accounts (1993) System of National Accounts 1993, Commission of the European Communities, IMF, OECD, UN, World Bank.

Kahneman, Daniel and Amos Tversky (1979) 'Prospect Theory: An Analysis of Decisions under Risk,' Econometrica, Vol. 47, No. 2, 263-291.

Luce, R. Duncan and Howard Raiffa (1957) Games and Decisions, 1985 Dover Edition.

Machina, Mark J. (1982) "Expected Utility" Analysis without the Independence Axiom,' Econometrica, Vol. 50, No. 2, 277-323.

Machina, Mark J. (1997) 'Choice under Uncertainty: Problems Solved and Unsolved,' in Partha Dasgupta and Karl-Göran Mäler, eds, The Environment and Emerging Development Issues, Vol. 1, Oxford: Clarendon Press, 201-255.

Machina, Mark J. (2001) 'Payoff Kinks in Preferences over Lotteries,' Journal of Risk and Uncertainty, 23:3, 207-260.

Marshall, Katherine (1998) 'The gambling industry: Raising the stakes', Services Indicators, Statistics Canada, 4th Quarter, 29-38.

Marshall, Katherine (2000) 'Update on Gambling,' Perspectives, Statistics Canada, Spring, 29-35.

Pratt, John W., Howard Raiffa, and Robert Schlaifer (1995) Introduction to Statistical Decision Theory, Cambridge: The MIT Press.

Quiggin, John (1993) Generalized Expected Utility Theory: The Rank-Dependent Model, Norwell: Kluwer Academic.

Rabin, Matthew (2000) 'Risk Aversion and Expected-Utility Theory: A Calibration Theorem,' Econometrica, Vol. 68, No. 5, 1281-1292.

Rabin, Matthew and Richard H. Thaler (2001) 'Risk Aversion,' Journal of Economic Perspectives, Vol. 15, No. 1, 219-232.

Samuelson, Paul A. (1952) 'Probability, Utility, and the Independence Axiom,' Econometrica, 20, 670-678. 
Segal, Uzi and Avia Spivak (1990) 'First Order versus Second Order Risk Aversion,' Journal of Economic Theory, 51, 111-125.

Simon, Jonathan (1999) 'An Analysis of the Distribution of Combinations Chosen by UK National Lottery Players,' Journal of Risk and Uncertainty, 17:3, 243276.

Starmer, Chris (2000) 'Developments in Non-Expected Utility Theory: The Hunt for a Descriptive Theory of Choice under Risk,' Journal of Economic Literature, Vol. XXXVIII, No. 2, 332-382.

Stern, Hal and Thomas M. Cover (1989) 'Maximum Entropy and the Lottery,' Journal of the American Statistical Association, Vol. 84, No. 408, 980-985.

von Neumann, John and Oskar Morgenstern (1953) Theory of Games and Economic Behavior, Princeton: Princeton University Press.

Walker, Ian (1998) 'The Economic Analysis of Lotteries,' Economic Policy, October, $359-401$.

Watt, Richard (2002) 'Defending Expected Utility Theory,' Journal of Economic Perspectives, 16:2, 227-230.

Yaari, Menahem E. (1987) 'The Dual Theory of Choice under Risk,' Econometrica, Vol. 55, No. 1, 95-115.

Ziemba, William T. (1986) Dr Z's 6/49 Lotto Guidebook, Vancouver: Dr. Z Investments Inc. 